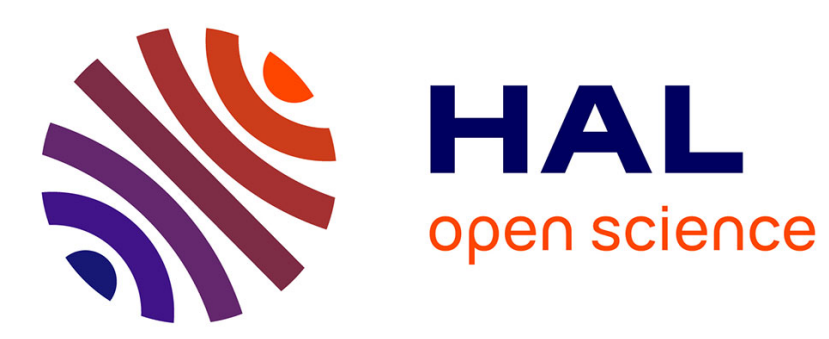

\title{
PHYSICAL MEASUREMENTS AND NUMERICAL EXPERIMENTS ON THE KETTLEDRUM
}

\author{
A. Ramdane, A. Chaigne
}

\section{To cite this version:}

A. Ramdane, A. Chaigne. PHYSICAL MEASUREMENTS AND NUMERICAL EXPERIMENTS ON THE KETTLEDRUM. Journal de Physique IV Proceedings, 1992, 02 (C1), pp.C1-55-C1-58. 10.1051/.jp4:1992108 . jpa-00251050

\section{HAL Id: jpa-00251050 https://hal.science/jpa-00251050}

Submitted on 1 Jan 1992

HAL is a multi-disciplinary open access archive for the deposit and dissemination of scientific research documents, whether they are published or not. The documents may come from teaching and research institutions in France or abroad, or from public or private research centers.
L'archive ouverte pluridisciplinaire HAL, est destinée au dépôt et à la diffusion de documents scientifiques de niveau recherche, publiés ou non, émanant des établissements d'enseignement et de recherche français ou étrangers, des laboratoires publics ou privés. 


\title{
PHYSICAL MEASUREMENTS AND NUMERICAL EXPERIMENTS ON THE KETTLEDRUM
}

\author{
A. RAMDANE and A. CHAIGNE \\ Groupe Acoustique, Département Signal, TELECOM Paris, 46 rue Barrault, F-75634 Paris cedex 13, \\ France
}

\begin{abstract}
Experimental data derived from measurements performed on a kettledrum are taken into account in order to elaborate a synthesis program based on physical knowledges. Some particularly relevant features of the kettledrum, such as the coupling between the membrane and the kettle, the nonlinearity of the mallet and the influence of the striking position are carefully investigated.
\end{abstract}

\section{Physical measurements.}

First, the enclosed volume of air inside the kettle is set into vibration by an external loudspeaker driven by a random noise generator. The vibrations of the membrane are damped with the help of a light glass wool mattress. The internal modes are identified from FFT analysis carried out on the signal delivered by a microphone located inside the kettle. Removing further the glass wool shows the influence of the load by the membrane on the modal parameters of the cavity. In a second series of experiments, the kettledrum is excited in a standard way. The membrane vibrates freely after a short interaction with a mallet. The force imparted by the mallet and the motion of the membrane are measured by means of appropriate transducers. The pressure is recorded by a second microphone located outside the kettle at roughly the same distance from the instrument than the ears of the player. From these experiments the radiation efficiency of the main eigenmodes of the instrument are evaluated. Both series of experiments are carried out in an anechoic room. In Figure 1, one can see typical pressure spectra obtained in various situations with the same mallet (Vibrawell C6-12). Fig.1-a represents the external sound spectrum for a light striking (initial velocity $V_{H O}=1 \mathrm{~m} / \mathrm{s}$ ) near the center. Fig. 1-b shows the modifications in this spectrum for a stronger impact $\left(\mathrm{V}_{\mathrm{HO}}=3 \mathrm{~m} / \mathrm{s}\right)$. In Fig 1-c, one can see that a light striking $\left(\mathrm{V}_{\mathrm{HO}}=1 \mathrm{~m} / \mathrm{s}\right)$ of the membrane near the edge provides us with a nearly harmonic spectrum, which leads in turn to a well-defined pitch. Like in Fig 1-b, the drastic changes in the spectral content in Fig. 1-d are due to the nonlinearity of the felt, for a striking near the edge with $\mathrm{V}_{\mathrm{HO}}=3 \mathrm{~m} / \mathrm{s}$.

\section{Synthesis.}

The main results of the experiments are integrated into the synthesis program. Here the wave equation of the membrane is sampled in space and time by means of a finite differences method described in a previous paper [1]. This efficient method providesus with synthesized sounds in the time domain. The most salient modes of the kettle are simulated by second-order mechanical filters which are spatially distributed on the surface of the membrane. The excitation force is modeled by a nonlinear compression law of the felt. The frequency dependence of the internal losses are approximated by a second-order polynom, following the method described elsewhere [2]. The auditory comparison between real and synthesized sounds highlights the perceptual relevance of three major features of the instrument : the intermodal coupling, the nonlinearity of the mallet and the striking position. 

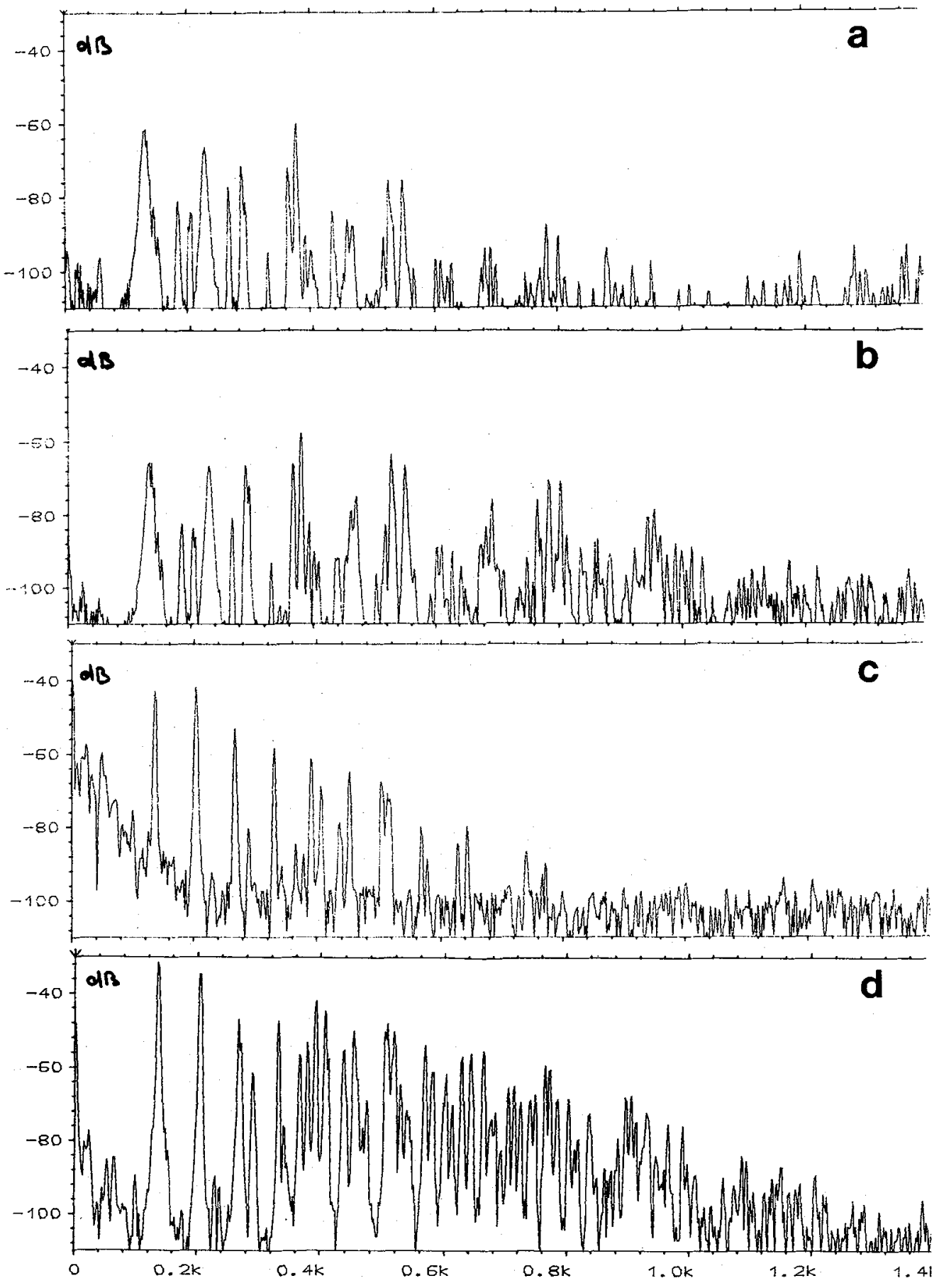

Fig.1 : External sound pressure spectra . a) light impact (center); b) strong impact (center); c) light impact (edge) d) strong impact (edge). Frequency scale : $1.4 \mathrm{kHz}$. 


\section{Results.}

Figure 2 shows a comparison between measured (a) and simulated (b) acceleration of the impact mallet (Vibrawell C6-12), for an initial velocity of $1.6 \mathrm{~m} / \mathrm{s}$ (mf) near the edge. The numerical model accounts for the impact duration as well as for the value of the maximum. In the synthesis, the interaction force is assumed to be roughly equal to the product of this acceleration by the total mass $\mathbf{M}_{\mathrm{m}}$ of the mallet. Striking near the center of the membrane leads to a more distorted plot, due to the rebound (see Figure 3). The simulation (Figure 3-b) reproduces this feature very well.
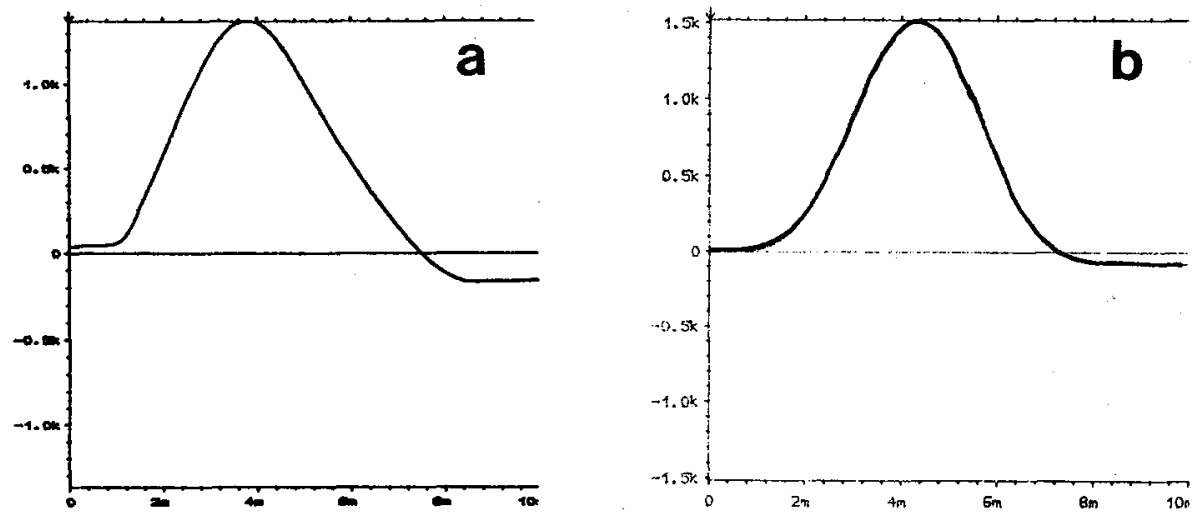

Figure 2. Impact acceleration near the edge; a) measured. b) simulated. Time scale : $10 \mathrm{~ms}$.
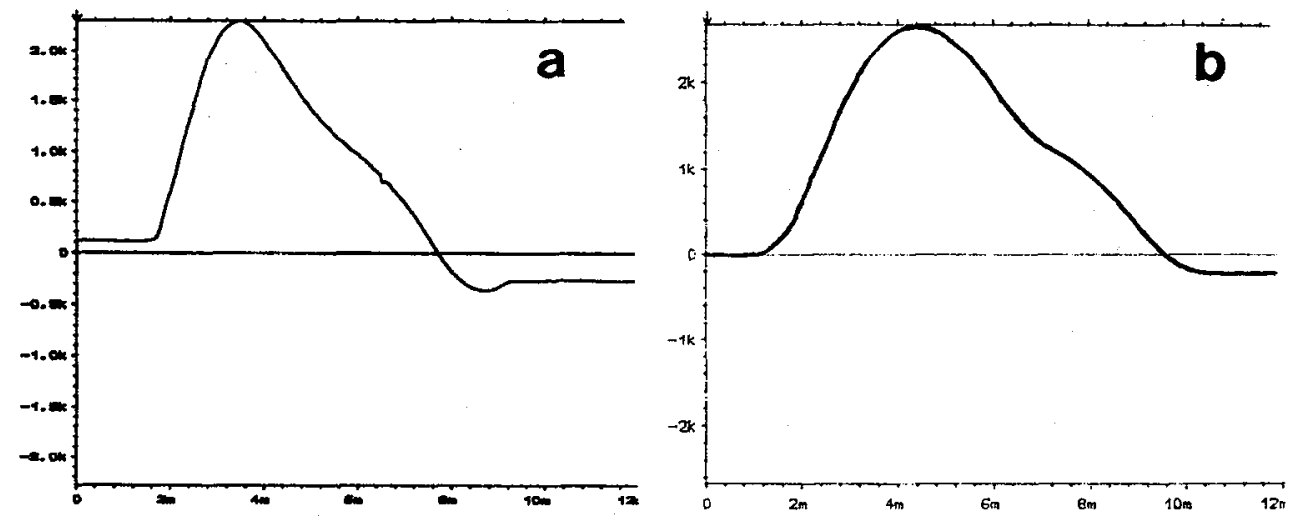

Figure 3. Impact acceleration near the center, a) measured. b) simulated. Time scale :12 ms

Figure 4 illustrates the nonlinearity of the felt compression. Figure 4-a shows the spectrum of the simulated displacement of the membrane for an initial velocity of the mallet of $V_{H 0}=1.0 \mathrm{~m} / \mathrm{s}$, near the edge, whereas Figure 4-b represents the spectrum of the simulated displacement for $V_{H 0}=4.0 \mathrm{~m} / \mathrm{s}$. It is plain that the nonlinear excitation not only modifies the level of the response, but also its spectral content. Figure 5 shows the results of the Prony analysis [3] for the estimation of the damping factors of the main modes. For an excitation near the center, the symmetrical modes of the membrane are strongly coupled with the modes of the cavity, and exhibit therefore relatively high damping (upper curve : thick line). In the normal use of the instrument, $i$. e. for a striking position at $r / 4$ from the edge (where $r$ is the radius of the membrane) only a few number of modes remain coupled with the cavity and the damping is mainly due to the polymer itself (lower curve : thin line). In this context, the dashed line represents the parabolic approximation of the internal losses $b_{1}+b_{3} \omega^{2}$ which is of particular interest for time-domain simulations [2]. 

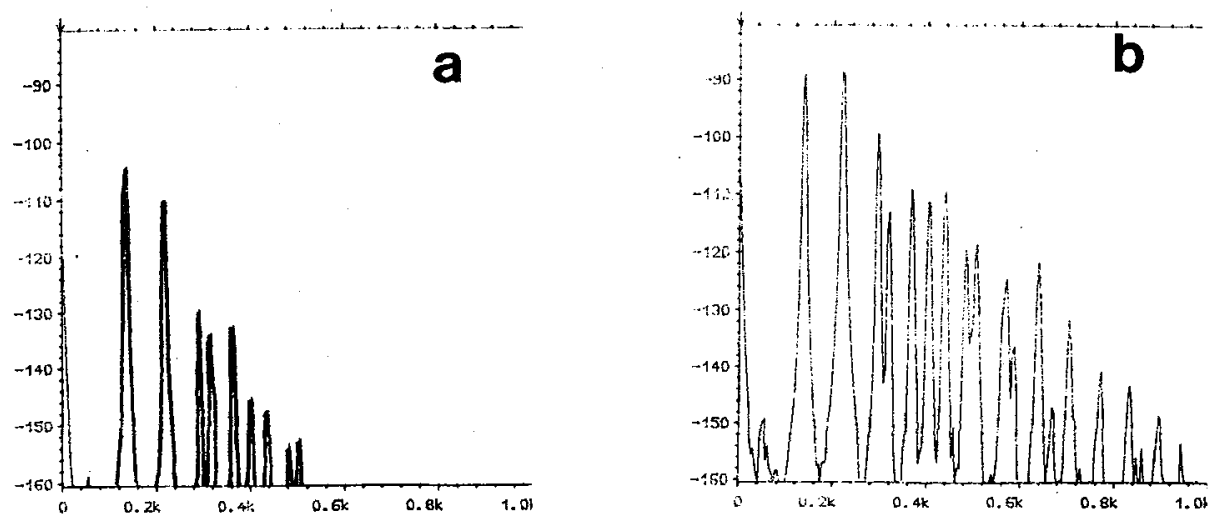

Figure 4 : FFT-spectrum of the simulated displacement near the edge.

a) $\mathrm{V}_{\mathrm{HO}}=1 \mathrm{~m} / \mathrm{s}$. b) $\mathrm{V}_{\mathrm{HO}}=4 \mathrm{~m} / \mathrm{s}$. Frequency scale $: 1 \mathrm{kHz}$.

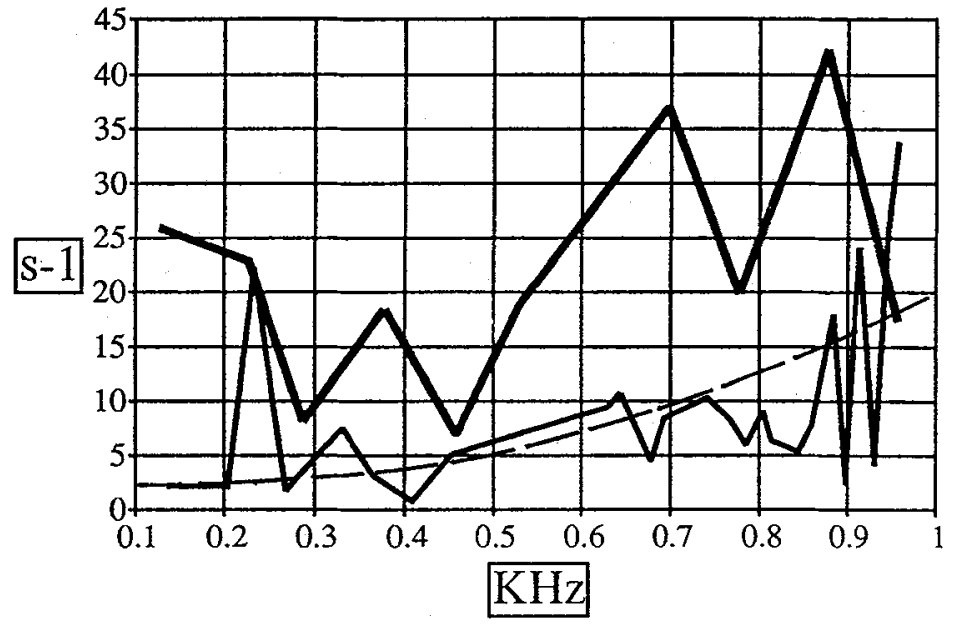

Figure 5 : damping factors of the main modes. Frequency scale : $1 \mathrm{kHz}$.

Center excitation (Thick line); Edge excitation (thin line); Numerical model (dashed line).

\section{References.}

[1] A. Ramdane, "Synthese sonore de sons de timbale", Actes du Premier Congrès Français d'Acoustique, Lyon, 1990.

[2] A. Chaigne, "On the use of finite differences for the synthesis of musical transients. Application to plucked stringed instruments", J. Acoustique, 1991 (submitted).

[3] J. Laroche, "Etude d'un système d'analyse et de synthèse utilisant la méthode de Prony. Application aux instruments de type percussif", Thèse de doctorat de TELECOM Paris, 1989. 